reached I think it were well to prescribe the procedure at certain stages.

But, after all, no amount of careful attention to any analytical process is of much avail unless the materials used are of good quality. Too many chemists, as appears from the replies furnished in the present case, assume, without positive knowledge, that those used by them are satisfactory; others report one or the other as of good quality without giving any quantitative data in support of such an assertion. No chemist can be said to do justice to his employers or patrons who does not know what order of error his results may include, arising from impurities in reagents and the solvent action of those reagents on his utensils, or from other causes either preventable or admitting of exact correction. Too often, beyond doubt, is a known contamination thoughtlessly excluded as negligible when, in fact, a quantitative test might have shown the falsity of the belief.

\title{
FOURTH SESSION OF THE INTERNATIONAL COMMISSION FOR UNIFORM METHODS OF SUGAR ANALYSIS.
}

\author{
HELD IN BERLIN, GERMANY, JUNE 4, I9O3. \\ Received Septerriber 22, 1903.
}

The following were present:

Professor Dr. A. Herzfeld, chairman.

Privy councilor, Prof. Dr. Landolt, Berlin.

Baron von Donner, chairman of the Verein der am Zuckerhandel betheiligten Firmen, Hamburg.

Privy Councilor Koenig, chairman of the board of directors of the Verein der Deutschen Zuckerindustrie, Berlin.

Professor Dr. Brodhun, representative of the PhysikalischTechnische Reichsanstalt, Berlin.

Professor Dr. Schoenrock, idem, Berlin.

Privy Councilor Professor Dr. von Buchka, delegate of the Kaiserliche Reichssihatzant, Berlin.

Government Councilor Weinstein, representative of the Kaiserliche Normal Aichungsant, Berlin.

Government Councilor F. Strohmer, Vienna, Austria. 
J. Ragot, director of the Syndicat des Fabricants de Sucre de France.

K. Fischmann, director of the Russian Sugar Manufacturers' Association, Kiev.

Dr. Raschkowitsch, director of the chemical laboratory of the Russian Sugar Manufacturers' Association, Kiev.

François Sachs, representative of the Société Technique et Chimique de Sucrerie de Belgique, Brussels.

Dr. F. G. Wiechmann, representative of the American Sugar Refining Company, New York.

E. Silz, representative of the Association des Chimistes de Sucrerie et de Distillerie de France, Paris.

A Watt, member of the Beetroot Sugar Association of Lancashire, Liverpool, England.

S. Stein, member of the Beetroot Sugar Association of Lancashire, Liverpool, England.

Also the following members of the Commission:

Dr. C. Ahrens, Hamburg; Lobry de Bruyn, Amsterdam; Professor Dr. Frühling, Braunschweig; Dr. G. Götting, Breslau; Dr. B. Hermann, Hamburg; F. Herles, Prague; Dr. A. Langfurth, Altona; Dr. O. Wendel, Magdeburg; Dr. R. Woy, Breslau, as well as numerous other chemists connected with the sugar industry.

After the opening of the session, the chairman expressed his special thanks to Privy Councilor Landolt, the scientific founder of the polariscopic method, as well as to Baron von Donner, and to Privy Councilor Koenig, for their coming. The chairman then outlined the previous work of the Commission.

He requested Mr François Sachs, of Brussels, and Dr. F. G. Wiechmann, of New York, to again undertake the editing of the French and of the English text of the proceedings.

The sets of quartz-plates which had been selected by the Physikalisch-Technische Reichsanstalt in Berlin, and which had been tested in the laboratory of the Verein der Deutschen Zuckerindustrie as to their sugar value, have been distributed to proper central stations of the countries interested, and there are kept at the disposal of chemists. These plates have been tested in almost all of the countries which have received the sets, and have been 
found correct. Some of these stations have thus far not made a report as to the results of this reexamination, and such a report is, therefore, requested.

Execution of the Paris agreement, according to which chemically pure sugar is to be utsed for the adjustment of polariscopes and for the testing of plates, has, in some countries, met with difficulties because they could not succeed in preparing chemically pure sugar. The laboratory at Berlin, therefore, offers to furnish chemically pure sugar.

In the determination of invert-sugar, a difficulty has arisen. inasmuch as the English chemists have, of late, again declared against the clarificaticn with basic lead acetate; the Commission will, therefore, have to seek means and methods to prevent, in this respect, loss of uniformity, now secured in the methods of analysis.

\section{THE D.H'S PROCEEDINGS.}

(I) "Report concerning practical experiences made with the uniform methods of analysis agreed upon in Paris."

Doctor Hermann delivered an address on this topic; this is published in the Zeitschrift des I'ereins der Deutschen Zuckeriniustric. The speaker was of the opinion that numerical proofs of the success of the Paris agreement could not be adduced, yet the fact could be stated that the differences have decreased in number. To avoid a warming of the polariscope tubes in handling, he recommended covering the same with rubber.

Privy Councilor Professor Dr. von Buchka made the following statements :

The International Commission for Uniform Methods of Sugar Analysis decided, in the year Igoo, that the determination of invert-sugar in raw sugars is to be carried out according to the method of Prof. Dr. A. Herzfeld. It scems desirable to abandon this method and to prepare Fehling's solution in such a manner that the weighed constituents be brought into solution with water. up to one liter. This would be in accordance with the method otherwise customary in the preparation of normal solutions. This method of procedure has, moreover, been aclopted in the official directions for the analysis of wine. decreed in Cermany in the year 1896 . It seems desirable that the manner of preparing Fehling's solution be always the same, whatever purpose the sugar determinations may have to serve. 
Professor Dr. Herzfeld replied that Herzfeld's method differs from the method used in the examination of wines, not only in the manner of preparing Fehling's solution, but also in the employment of a definite heating surface. A further essential difference is the fact that the reaction is suddenly interrupted after two minutes by the introduction of cold water. On this account all tables which have been prepared by Meissl and others are of no value, unless one is also willing to return not only to Soxhlet's Fehling's solution, but also to the antiquated working methods for which these tables have been established.

In the determination of invert-sugar, the Io grams of canesugar which are dissolved in Fehling's solution exert a great influence on the amount of copper reduced. It would, therefore, be dangerous to alter the concentration of the solution before this influence shall have been carefully studied, and a decision arrived at as to whether it might not be necessary to establish a new table for the solutions made thus differently.

Mr. Pellet declares himself as opposed to the use of basic lead acetate as a clarifying reagent, and for the heating of the solution to reduce the copper on the water-bath, instead of over the naked flame.

Government Councilor Strohmer believed that he might declare in the name of the Austrian chemists that they agree with the remarks made by Professor Herzfeld, for a change in the manner of preparing Fehling's solution would necessitate a change of tables for the determination of invert-sugar, that is to say, would amount to a change of the method itself. Commerce has adopted Herzfeld's method. Each produce-exchange demands, in the certificate, determinations of invert-sugar according to Herzfeld. If the method were to be changed, the consent of commerce would have to be secured. It was the determination of invert-sugar which held back, for so long, the introduction of uniform methods, and Mr. Strohmer expresses the wish that this agreement, which was so difficult to bring about, may not again be disturbed so soon by the introduction of a new method of preparing Fehling's solution. Dr. Woy next presented an additional report ( $a d . r$.) of the day's program. He, too, is unable to present data which cover all Germany, but in a compilation of Silesian analyses, made in duplicate, he made the observation that series of analyses which 
were in excellent agreement were suddenly interrupted by series which exhibited serious differences, and that in such cases the super-analysis also cid not tally with the series of the former analyses, but at times represented an accurate average. In such cases only the samples can have been the cause of the differences.

He recommends the collecting of such cases in order to determine, numerically, how often greater differences arise and whether, in such cases, the fault is to be ascribed to the method, the analyst, or the taking of the sample. Furthermore, he desires a more exact definition of the maximum amount of basic lead acetate, and of aluminum hydrate, allowable, in order to exclude, as far as posible, the source of error inherent in the volume of the precipitate.

Dr. Koehler-Maltsch was of the opinion that differences which still occur in polarizations must be ascribed to faulty graduation of the flasks.

The Commission decided to elect a Sub-commission for the elucidation of the questions at issue. This Sub-commission is to consist of Messrs. Watt, Wiechmann and Strohmer, and is to study especially the question of clarification by basic lead acetate, as well as the question of a change in Fehling's solution. Privy Councilor von Buchka promises his assistance in these investigations.

(II) "The valuation of 'Sand' and 'Krystallzucker" in International trade."

Government Councilor Strohmer, of Vienna, discussed this question. His lecture is printed in the Zeitschrift des Vereins der Deutschen Zuckerindustrie. The address evoked no discussion.

(III) "Introducticn of International uniform directions for sampling raw sugars." Mr. Wiechmann stated that he considered it to be very desirable that a roo per cent. sample be taken, that is to say, a sample from every package wherever this may prove at all possible. Furthermore, he added that great attention ought to be paid to the manner in which samples are taken, for, otherwise, very peculiar results would be secured, especiaily with raw sugars of lower grades.

Director S. Stein, Liverpool, explained that in England sugar, on importation, has to pay duty according to polarization. It is of 
great importance that for this purpose the same sample be used which is used in effecting the purchase. The English authorities found very marked differences between their analyses and the results which the refineries declared. The cause of this is to be sought in the different manner of sampling the sugar. It is very difficult to obtain a correct average sample, especially of cane-sugar. As is known, cane-sugar is put up in different kinds of packages. For instance, in bags, in mats, in hogsheads, etc. Furthermore, a cane-sugar is not homogeneous, but varies in composition in different parts of the package. Thus, in canesugar, syrups and semifluid masses occur. All this has to be taken into consideration. It is necessary that the sampling be done in such a manner that the sample drawn be truly representative of the sugar. Sampling shall be done in such a way that the sample shall be taken from different parts of the package, and at one time. It is well known that stored sugar changes its composition. A sugar which has a certain composition to-day has a different composition one or two months hence. It is also necessary that the sampling be done on a given number of bags or packages. Mr. Stein, therefore, advised the adoption of a resolution or the addressing of a request to the International Commission to consider what points of view should necessarily be borne in mind in order that uniform sampling, especially of canesugars, may be achieved. The speaker is confident that the conclusions of such a forum, in this most important matter, would prove binding and elucidating.

At the request of the chairman, Mr. Wiechmann agreed to prepare a compilation of the different directions which are in force in the various countries interested in the sugar industry, and to submit this preliminary report to the Sub-commission, consisting of Messrs. Wiechmarn, Watt and Strohmer.

It was the general opinion that it was necessary to consult expert chemists more than has been done heretofore in the drawingup of working directions for samplers.

(IV) and (V) "Influence of temperature on the specific rotation of sucrose," and "Introduction of temperature-corrections when the temperature of observation differs from the temperature of $20^{\circ} \mathrm{C}$., which has been accepted as the normal temperature." These two topics were disposed of together. 
Dr. Schoenrock discussed the first-named of these subjects. His address is printed in the Zeitschrift des Vereins dor Deutschon Zuckerindustrie.

In the discussion of this address, Mr. Wiechmann, while expressing appreciation of Schoenrock's labors, declared against the introduction of corrections to polarizations obtained in actual practice. Professor Herzfeld took the same position, because, besides the variations in specific rotation, still other factors come into play, for instance, the variable amount of evaporation which takes place on filtering the solution.

Professor Brodhun remarked that, if correct corrections are applied, correct results must be obtained. It was decided that the individual members of the Commission, for the present, are to study the question of corrections on their own account.

(VI) "Determinations of the sugar subject to duty or bounty contained in saccharine products and fruit preserves."

In this connection, the chairman read a paper prepared by $\mathrm{Mr}$. $\mathrm{H}$. W. Wiley, of Washington, who, to the regret of those assembled, was prevented from attending. The chairman closed his remarks with the words that the point of view taken by Mr. Wiley would probably meet with the unanimous approval of the Commission. There was no objection to this comment.

(VII) "Chemical control as an aid to the Entrepot-system sanctioned by the Brussels convention."

The printed address of Professor Herzfeld, on this subject, was in evidence. It also appeared in the Vereinszeitschrift. There was no debate on this address.

The following papers, which figured on the program of the Congress of Applied Chemistry, were also disposed of during the session of the Commission.

(I) Lecture of Mr. Wiechmann on "A restant source of error in optical sugar analysis." The question of the influence of the basic lead acetate precipitate, discussed by Mr. Wiechmann, is to be further studied.

(2) Lecture of Mr. Dupont: "Sur 1' unification des échelles saccharimétriques et l'adoption d'une échelle á poids normale de 20 grammes."

Mr. Dupont was not present. Decision on his proposition to introduce a normal weight of 20 grams is deferred. 
(3) and (4) A paper by Mr. David R. Davoll: "A study in the determination of raffinose," and a paper by the same, "Should rafifinose be considered as non-sugar in calculating the quotient of purity?" were presented in print. 'There was no discussion of these papers.

(5) A lecture by Mr. Sachs: "Shall chemical measuring instruments be graduated according to the old Mohr method, of according to the new official method of France and Germany?" A discussion followed this address. Professor Weinstein and Privy Councilor von Buchka stated their opinion to be that a single section should not adopt a resolution in this matter, and declared a return to Mohr's method a step backwards. Mr. François Sachs disputed the latter assertion.

The meeting then adjourned.

F. G. Wiechmann, Secretary.

\section{NOTE.}

On the Emulsifying Action of Soap.-Experiments on the emulsifying power of soap solutions have been recently published by $H$. W. Hillyer. ${ }^{1}$ In these it is shown that the effect is due to the lowering of the interfacial tension at the interface oil-soap solution, caused by the non-hydrolyzed soap contained in the aqueous solution. The variation of interfacial ension with the concentration of the soap solution was quantitatively studied by Hillyer by means of a dropping pipette.

It may be remarked, however, that not only have exactly similar conclusions been arrived at previously by me, but they have been obtained by an almost identical method and pulished in one of the most universally read scientific journals. ${ }^{2}$

Doubtless my paper must have escaped Mr. Hillyer's notice, for in his second paper he refers to himself as a pioneer. In my experiments, drops of a neutral, fatty oil (or of a neutral hydrocarbon oil) containing a specified amount of free aliphatic acid were allowed to ascend through an alkali solution of known strength. My first experiments (not published) were made by

t This Journal, as, 5 t 1,524 ( 5903$)$.

2 Ztschr. phys. Chem., 31, 42 (1899). 